\title{
SISTEM PAKAR MENDETEKSI PENYAKIT PADA TANAMAN SAYUR SAWI DENGAN METODE BAYES
}

\author{
Friska Nainggolan' ${ }^{1}$, Harvei Desman Hutahaean ${ }^{2,}$, Asaziduhu Gea ${ }^{3}$ \\ ${ }^{1,2}$ TeknikInformatika STMIK Pelita Nusantara \\ ${ }^{3}$ Teknik Informatika, Universitas Methodist Indonesia \\ Frizkanainggolan94@gmail.com¹,Harvei.hutahaean@gmail.com². \\ gea.asaziduhu@gmail.com ${ }^{3}$
}

\begin{abstract}
Mustard vegetables are classified as leaf vegetables from the Cruciferaefamily which have high economic value and are very popular among the people. Mustard vegetables are often used by people as processed ingredients in various types of cuisine. In general, Vegetable Vegetables are planted in the lowlands to the highlands and harvest is done at the age of 30 - 60 days after planting, depending on the variety. Expert systems are systems that try to adopt human knowledge to computers, so that computers can solve problems as usual by experts. Bayes method is one of the methods found in expert systems that can calculate or process the probability values of each symptom. The expert system detects mustard plant disease has 5 types of diseases found in mustard vegetable plants, namely seedlings, leaf rot, clubroot, leaf spot, alternaria rot.
\end{abstract}

Keywords: Expert System, Bayes Method, mustard greens.

\section{PENDAHULUAN}

Sayur Sawi di Indonesia merupakan komoditi yang dapat di ekspor ke luar negeri. Sebagai komoditi ekspor tentu harus memiliki kualitas yang bagus.Sayur Sawi adalah salah satu tanaman yang rentan terkena penyakit. Hampir semua Sayur Sawi yang ada saat ini belum ada yang memiliki daya tahan kuat bila sudah terserang. Untuk mengatasi hal tersebut, salah satu hal yang harus diketahui oleh petani agar mampu memenuhi syarat kualitas maupun kuantitas produk pertanian adalah mengetahui jenis-jenis penyakit pada tanaman berdasarkan gejala-gejala yang muncul pada tanaman agar mampu menghindarinya maupun mengatasi penyakit tersebut.Permasalahan yang dihadapi adalah petani mengalami kesulitan dalam menentukan jenis penyakit yang menyerang tanaman sayur sawi, Hal ini menjadi permasalahan ketika tidak diatasi dengan benar karena dapat menyebabkan tanaman mati atau tidak tumbuh dengan baik.Oleh karena itu dunia pertanian dan teknologi informasi sudah memilki keterkaitan dalam hal penyediaan informasi yang akan membantu para petani,dalam kesempatan ini akan dirancang sistem pakar untuk mendeteksi penyakit tanaman sayur sawi dengan menggunakan metode bayes, dan sistem pakar ini adalah salah satu sistem yang telah terkomputerisasi yang diharapkan mampu membantu pada petani dalam mengenali berbagai penyakit pada tanaman sayur sawi berdasarkan gejala-gejala yang muncul pada tanaman sayur sawi.

Salah satu cara untuk mendeteksi penyakit pada tanaman sayur sawi dengan memanfaatkan perkembangan teknologi dan informasi yaitu dengan mengembangkan ilmu kecerdasan buatan (Artificial Intteligence), salah satunya adalah sistem pakar. Sistem pakar ini adalah salah satu sistem yang telah terkomputerisasi yang dapat membantu mendeteksi penyakit pada tanaman sayur sawi yang diharapkan mampu membantu para petani sayur sawi dalam mengenali berbagai penyakit pada tanaman sayur sawi berdasarkan gejala-gejala yang muncul pada tanaman sayur sawi.

Metode bayes adalah salah satu pendekatan untuk sebuah ketidaktentuan yang diukur dengan probabilitas atau kemungkinan. Metode bayes dipilih dalam perancangan sistem pakar mendeteksi penyakit pada tanaman sayur sawi karena pada metode bayes, dibutuhkan informasi-informasi dalam bentuk nilai probabilitas untuk setiap alternatif yang ada pada persoalan yang sedang dihadapi yang nantinya akan menghasilkan nilai harapan sebagai dasar pengambilan keputusan. Dalam studi kasus yang dibahas dalam penelitian ini, berbagai gejala yang muncul pada tanaman sayur sawi akan dihitung menggunakan rumus atau ketentuan pada metode bayes untuk menarik kesimpulan tentang penyakit pada tanaman sayur sawi tersebut.

Dengan adanya aplikasi sistem pakar mendeteksi penyakit pada tanaman sayur sawi, maka petani dengan mudah mendapatkan informasi tentang penyakit tanaman sayur sawi.

\section{METODE}

1. Metode Bayes Metode bayes adalah metode yang digunakan 
untuk menghitung probabilitas terjadinya suatu peristiwa berdasarkan pengaruh yang didapat dari hal observasi ${ }^{[1]}$.

\section{Sistem Pakar}

Sistem pakar merupakan sistem yang berusaha mengadopsi pengetahuan manusia ke komputer, agar komputer dapat menyelesaikan masalah seperti yang biasa dilakukan oleh para ahli $\left.{ }^{[2}\right]$. Diharapkan dengan sistem pakar ini, pengguna dapat menyelesaikan masalah tertentu, tanpa bantuan para ahli dalam bidang tersebut.

Bagian dari sistem pakar adalah terdiri dari 2 komponen utama yaitu knowledge base yang berisi knowledge dan inferensi yang menggambarkan kesimpulan. Kesimpulan tersebut merupakan respons dari sistem pakar atau permintaan pengguna ${ }^{[2]}$

3. Probabilitas Bayes

Probabilitas bayes merupakan salah satu cara yang baik untuk mengatasi ketidakpastian data dengan menggunakan formula bayes yang dinyatakan dengan rumus sebagai berikut ${ }^{[8]}$

$\mathrm{P}(\mathrm{A} \mid \mathrm{B})=\frac{\mathrm{P}(\mathrm{B} \mid \mathrm{A}) * \mathrm{P}(\mathrm{A})}{\mathrm{P}(\mathrm{B})}$

Dengan :

P $(\mathrm{A} \mid \mathrm{B})$ : probabilitas A dan B terjadi bersamasama

$\mathrm{P}(\mathrm{B} \mid \mathrm{A})$ : probabilitas B dan A terjadi bersamasama

P (B) : probabilitas kejadian B

Langkah-langkah dalam menerapkan Metode Bayes dalam sistem pakar adalah ${ }^{[9]}$ :

a. Menginput gejala-gejala yang diketahui oleh user, kemudian mencari nilai semesta dengan menjumlahkan probabilitas dari masing-masing gejala yang dialami atau dapat diformulasikan dengan rumus berikut:

$\sum_{i=1}^{n}=\mathrm{P}(\mathrm{E} \mid \mathrm{H} 1)+\mathrm{P}(\mathrm{E} \mid \mathrm{H} 2)++\mathrm{P}(\mathrm{E} \mid \mathrm{Hn})$

b. Setelah diketahui hasil penjumlahan diatas, kemudian menghitung nilai probabilitas hipotesis $\mathrm{H}$ tanpa memandang gejala/evidence apapun yaitu sebagai berikut:

$\mathrm{P}(\mathrm{Hi})=\mathrm{P}(\mathrm{E} \mid \mathrm{Hi})$

$\sum_{i=1}^{n}(P(E \mid H i)$

c. Setelah mengetahui hasil dari $\mathrm{P}$ (Hi) atau probabilitas hipotesis tanpa memandang gejala apapun, kemudian langkah selanjutnya adalah menhitung nilai probabilitas evidence $\mathrm{E}$ dengan rumus sebagai berikut:

$\mathrm{P}(\mathrm{E})=\sum_{k=0}^{n}=P(H i) * P(E \mid H i) \ldots \ldots$

d. Setelah mendapat nilai dari probabilitas evidence E, maka langkah selanjutnya adalah menghitung nilai bayes setiap hipotesis dengan rumus sebagai berikut:

$\mathrm{P}(\mathrm{Hi} \mid \mathrm{E})=\mathrm{P}(\mathrm{E} \mid \mathrm{Hi}) * \mathrm{P}(\mathrm{Hi})$

\section{$P(E)$}

e. Setelah mendapatkan seluruh nilai dari $\mathrm{P}(\mathrm{Hi} \mid \mathrm{E})$, maka langkah selanjutnya adalah menghitung total nilai bayes dengan rumus sebagai berikut:

$$
\sum_{n=1}^{n} \text { Bayes } i=\text { Bayes } 1+\text { Bayes } 2+\text { Bayes } n
$$

f. Dan langkah terakhir adalah menghitung persentase dari total nilai bayes dengan rumus sebagai berikut:

Persentase $=\quad \sum_{i=1}^{n}$ Bayes $i * 100 \% \ldots \ldots$.

\section{Penyakit Pada Tanaman Sayur Sawi}

Penyakit pada tanaman sayur sawi adalah

a. Penyakit Rebah Semai

b. Penyakit Busuk Daun

c. Penyakit Akar Gada

d. Penyakit Bercak Daun

e. Penyakit Busuk Alternaria

\section{Hasil dan Analisa}

1. Tabel Gejala

Tabel gejala merupakan tabel yang berisi gejala penyakit pada tanaman sayur sawi.

Tabel 1

Tabel Data Gejala

\begin{tabular}{|c|c|c|}
\hline $\begin{array}{l}\text { Kode } \\
\text { Gejala }\end{array}$ & Gejala & $\begin{array}{l}\text { Nilai } \\
\text { Probab } \\
\text { ilitas } \\
\text { Bayes }\end{array}$ \\
\hline G001 & $\begin{array}{l}\text { Pembusukan berwarna coklat } \\
\text { di bagian pangkal batang }\end{array}$ & 0.1 \\
\hline G002 & Layunya Tanaman & 0.3 \\
\hline G003 & $\begin{array}{l}\text { Bercak basah berwarna } \\
\text { coklat kehitanaman pada } \\
\text { daun }\end{array}$ & 0.6 \\
\hline G004 & Bercak semakin melebar & 0.8 \\
\hline G005 & Bentuk tidak teratur & 0.4 \\
\hline G006 & $\begin{array}{l}\text { Bagian akar yang terserang } \\
\text { terjadi pembengkakan yang } \\
\text { bentuknya seperti gada }\end{array}$ & 0.6 \\
\hline G007 & $\begin{array}{l}\text { Daun terdapat bercak } \\
\text { berwarna kuning hingga } \\
\text { kecoklatan bahkan berwarna } \\
\text { hitam }\end{array}$ & 0.6 \\
\hline G008 & Daun layu dan mati & 0.4 \\
\hline G009 & Akar tanaman kering & 0.4 \\
\hline G010 & Akar membusuk & 0.5 \\
\hline
\end{tabular}




\begin{tabular}{|l|l|l|}
\hline G011 & Kematian sawi tiba-tiba & 0.8 \\
\hline
\end{tabular}

\section{Tabel Rule}

Kaidah aturan atau rule base merupakan aturan yang bertujuan untuk menghubungkan gejala dengan penyakit yang terdapat pada tanaman sayur sawi. Rule base ini bertujuan untuk menarik kesimpulan tentang penyakit yang ada pada tanaman sayur sawi.

Tabel 2

Tabel Rule Base

\begin{tabular}{|c|c|c|}
\hline $\begin{array}{l}\text { Rule } \\
\text { Base }\end{array}$ & Gejala & $\begin{array}{c}\text { Jenis } \\
\text { Penyakit }\end{array}$ \\
\hline $\begin{array}{c}\text { Rule } \\
1\end{array}$ & $\begin{array}{l}\text { IF pembusukan berwarna } \\
\text { coklat di pangkal batang is } \\
\text { true } \\
\text { AND layunya tanaman is } \\
\text { true } \\
\text { THEN Rebah semai }\end{array}$ & $\begin{array}{l}\text { Rebah } \\
\text { Semai }\end{array}$ \\
\hline $\begin{array}{c}\text { Rule } \\
2\end{array}$ & $\begin{array}{l}\text { IF bercak basah berwarna } \\
\text { cokelat kehitaman pada } \\
\text { daun is true } \\
\text { AND bercak semakin } \\
\text { melebar is true } \\
\text { AND bentuk tidak teratur } \\
\text { is true THEN Busuk daun. }\end{array}$ & $\begin{array}{l}\text { Busuk } \\
\text { daun }\end{array}$ \\
\hline $\begin{array}{l}\text { Rule } \\
3\end{array}$ & $\begin{array}{l}\text { IF Bagian akar yang } \\
\text { terserang terjadi } \\
\text { pembengkakan yang } \\
\text { bentuknya seperti gada is } \\
\text { true THEN Akar gada. }\end{array}$ & Akar gada \\
\hline $\begin{array}{l}\text { Rule } \\
4\end{array}$ & $\begin{array}{l}\text { IF Daun tedapat bercak } \\
\text { berwarna kuning hingga } \\
\text { kecoklatan bahkan } \\
\text { kehitanaman is true } \\
\text { AND daun layu dan mati } \\
\text { is true THEN Bercak daun }\end{array}$ & $\begin{array}{c}\text { Bercak } \\
\text { daun }\end{array}$ \\
\hline $\begin{array}{c}\text { Rule } \\
5\end{array}$ & $\begin{array}{l}\text { IF Akar tanaman kering is } \\
\text { true } \\
\text { AND Akar membusuk is } \\
\text { true } \\
\text { AND Kematian tanaman } \\
\text { sawi tiba-tiba is true } \\
\text { THEN Penyakit busuk } \\
\text { alternaria. }\end{array}$ & $\begin{array}{l}\text { Penyakit } \\
\text { Busuk } \\
\text { alternaria }\end{array}$ \\
\hline
\end{tabular}

3. Contoh Studi Kasus

Seorang user menginput G009,G010 dan G011. Penyakit yang menyerang tanaman sayur sawi berdasarkan gejala tersebut nilai probabilitas bayes

Nilai probabilitas gejala $\mathrm{G} 009=0.4=\mathrm{P}(\mathrm{E} \mid \mathrm{H} 1)$, $\mathrm{G} 010=0.5=\mathrm{P}(\mathrm{E} \mid \mathrm{H} 2), \mathrm{G} 011=0.8=\mathrm{P}(\mathrm{E} \mid \mathrm{H} 3)$

Penyelesaian:

1. Mencari semesta dengan menjumlahkan probabilitas tiap-tiap gejala :

$$
\begin{aligned}
\sum_{\boldsymbol{n}=\mathbf{1}}^{\mathbf{3}} & =\boldsymbol{G 0 0 9}+\boldsymbol{G 0 1 0}+\boldsymbol{G 0 1 1} \\
= & 0.4+0.5+0.8 \\
= & 1.7
\end{aligned}
$$

2. Menghitung nilai probabilitas $H$ tanpa memandang evidenve apapun :

$$
\mathrm{P}(\mathrm{H} 1)=\frac{\mathrm{P}(\mathrm{E} \mid \mathrm{H} 1)}{\sum_{\boldsymbol{i = 1}}^{\boldsymbol{n}}(\boldsymbol{P}(\boldsymbol{E} \mid \boldsymbol{H} \mathbf{1}) 1.7}=0.4=0.235
$$

$$
\begin{array}{r}
\mathrm{P}(\mathrm{H} 2)=\frac{\mathrm{P}(\mathrm{E} \mid \mathrm{H} 2)}{\sum_{i=1}^{n}(\boldsymbol{P}(\boldsymbol{E} \mid \boldsymbol{H} 2) 1.7}=0.5=0.294 \\
\mathrm{P}(\mathrm{H} 3)=\underset{\sum_{i=1}^{n}(\boldsymbol{P}(\boldsymbol{E} \mid \boldsymbol{H} 3) 1.7}{\mathrm{P}(\mathrm{E} \mid \mathrm{H} 3)}=0.8=0.470
\end{array}
$$

3. Menghitung probabilitas evidence $\mathrm{E}$

$$
\begin{aligned}
& \sum_{\boldsymbol{k}=\mathbf{1}}^{\mathbf{3}}=\boldsymbol{P}(\boldsymbol{H i}) * \boldsymbol{P}(\boldsymbol{E} \mid \boldsymbol{H i}) \\
& =\boldsymbol{P}(\boldsymbol{H 1}) * \boldsymbol{P}(\boldsymbol{E} \mid \boldsymbol{H} \mathbf{1})+\boldsymbol{P}(\boldsymbol{H} 2) * \boldsymbol{P}(\boldsymbol{E} \mid \boldsymbol{H} 2)+ \\
& \boldsymbol{P}(\boldsymbol{H} \mathbf{3}) * \boldsymbol{P}(\boldsymbol{E} \mid \boldsymbol{H} \mathbf{3}) \\
& =0.235 * 0.4+0.294 * 0.5+0.470 * 0.8 \\
& =0.094+0.147+0.376 \\
& =0.617
\end{aligned}
$$

4. Menghitung nilai bayes setiap hipotesis

$\mathrm{P}(\mathrm{H} 1 \mid \mathrm{E})=0.4 * 0.235=0.1523$

$$
\begin{gathered}
0.617 \\
\mathrm{P}(\mathrm{H} 2 \mid \mathrm{E})=\underline{0.5 * 0.294}=0.2382 \\
0.617 \\
\mathrm{P}(\mathrm{H} 1 \mid \mathrm{E})=0.8 * 0.470 \\
0.617
\end{gathered}
$$

5. Setelah mendapatkan seluruh nilai bayes, maka langkah selanjutnya adalah menghitung total nilai bayes

$$
\begin{aligned}
& =0.4 * 0.1523+0.5 * 0.2382+0.8 * 0.6094 \\
& =0.06092+0.1191+0.48752 \\
& =0.66754
\end{aligned}
$$

6. Langkah terakhir adalah menghitung nilai persentase dari total nilai bayes yaitu :

$=0.66754 * 100 \%$

$=66.754 \%$ (Kemungkinan besar penyakit Busuk Alternaria)

\section{Implementasi Sistem}

a. Tampilan Form Login

Admin melakukan proses registrasi sebelum masuk ke menu admin: 


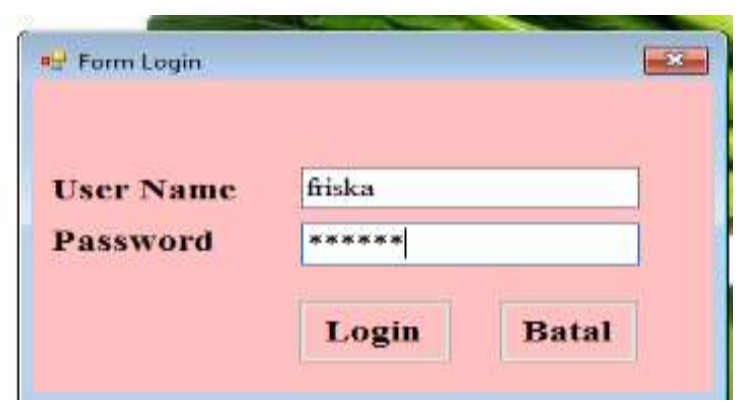

Gambar 2. Form Login

b. Tampilan form Menu

Form Menu adalah bagian yang berisi tentang data gejala, data penyakit, dan data rule.

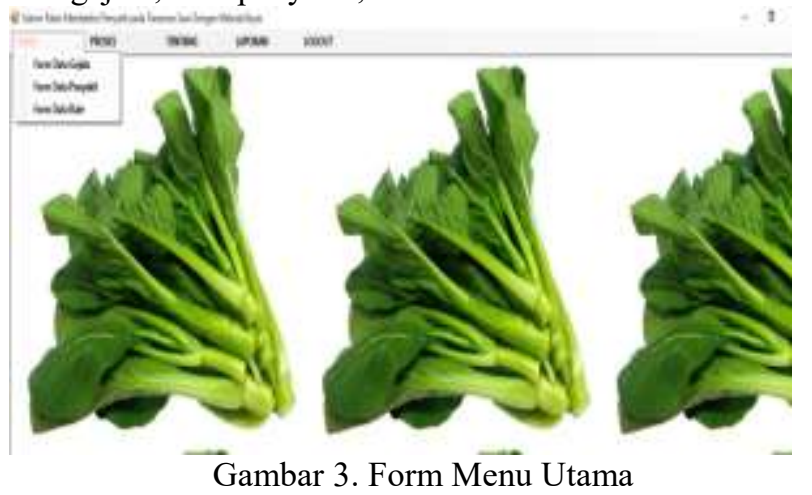

c. Tampilan Form Data Penyakit.

Form data penyakit form yang berisi 5 jenis penyakit pada tanaman sawi yang dilengkapi dengan button simpan, hapus, edit jika developer sistem akan melakukan perubahan terhadap data penyakit.

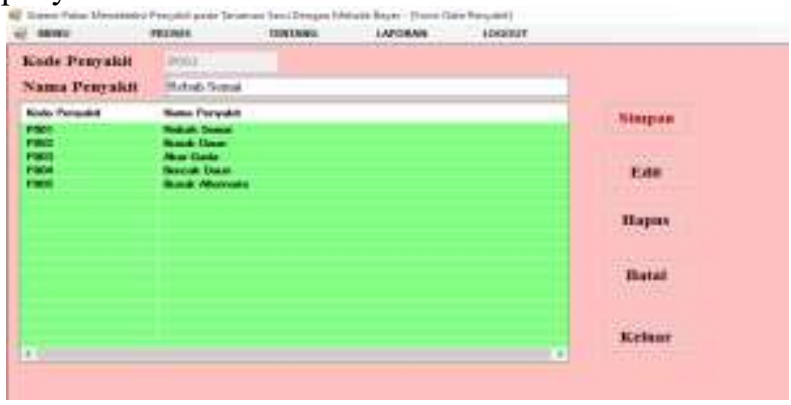

Gambar 4. Form Data Penyakit.

d. Tampilan Form Data Gejala.

Form data gejala form yang berisi tentang 11 gejala yang ada pada tanaman sawi.

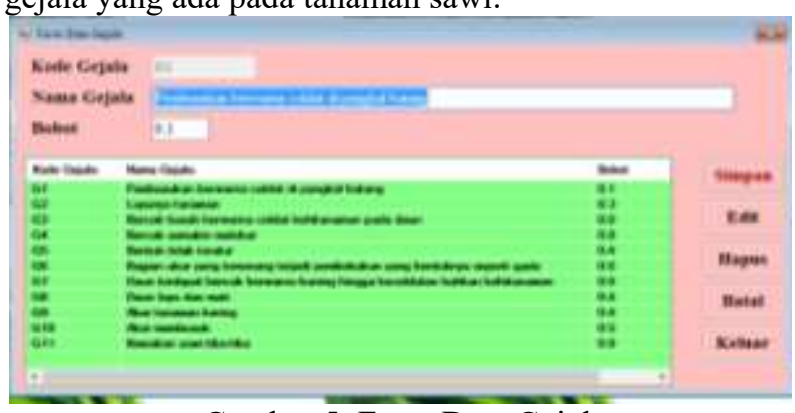

Gambar 5. Form Data Gejala e. Tampilan Form Rule

Form rule adalah form yang berisi tentang kaidah atau aturan-aturan gejala-gejala dalam menentukan jenis penyakit. Dalam form rule juga dilengkapi dengan button edit, hapus, simpan jika developer sistem akan melakukan perubahan terhadap rule. Berikut adalah tampilan form rule.

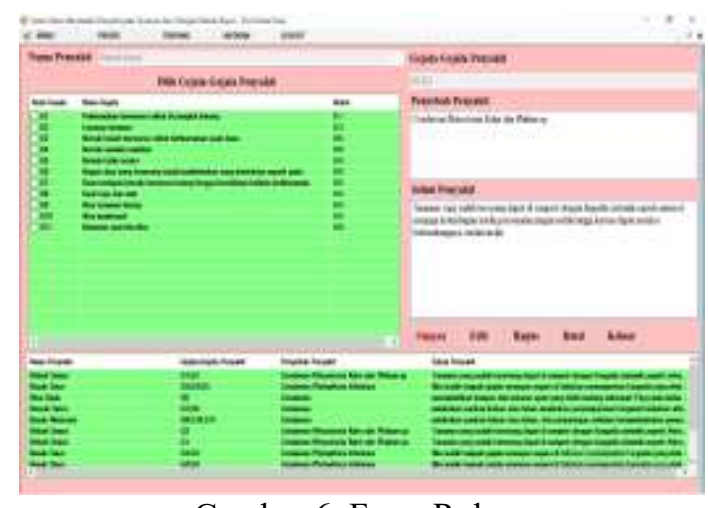

Gambar 6. Form Rule

f. Tampilan Form Konsultasi

Dalam form konsultasi, terlebih dahulu user mengisi data user yang terdiri dari nama, alamat, umur, dan pekerjaan. Selanjutnya user akan mencentang gejala-gejala yang ada pada tanaman sawi.

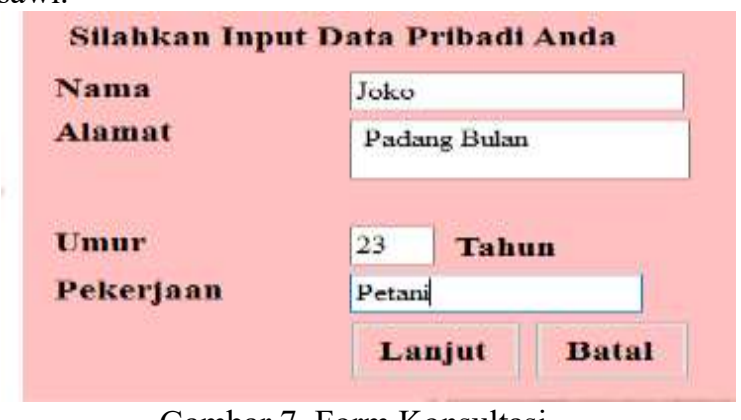

Gambar 7. Form Konsultasi

g. Tampilan Penginputan Data Gejala

Setelah Form penginputan Data Gejala tampil maka mencentang gejala-gejala penyakit yang di alamai tanaman sawi,selanjutnya di klik proses diagnosa penyakit sawi

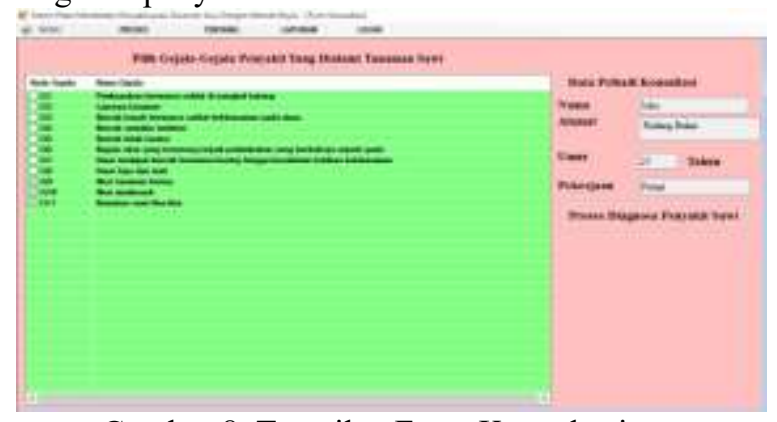

Gambar 8. Tampilan Form Konsultasi.

h. Halaman Hasil Konsultasi

Form hasil konsultasi form yang berisi hasil 
pengolahan gejala-gejala, yang diproses dengan metode bayes dan menghasilkan kesimpulan tentang jenis penyakit, probabilitas penyakit tersebut, penyebab, dan solusi dari penyakit tersebut.

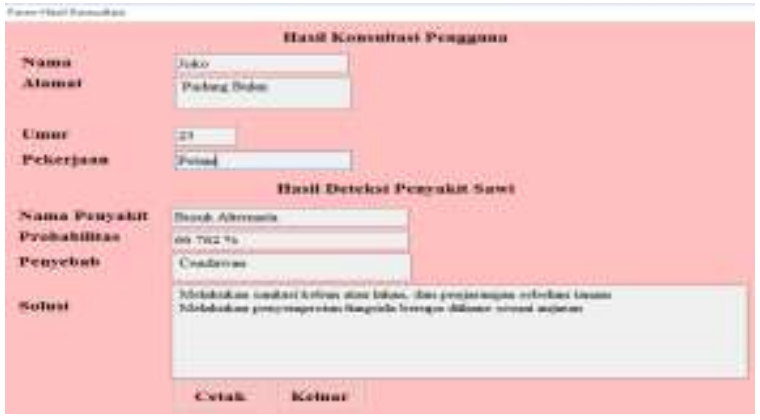

Gambar 9. Form Hasil Konsultasi

i. Hasil Laporan

Halaman report halaman hasil deteksi penyakit pada tanaman sawi dimana user dapat mencetak hasil tersebut.

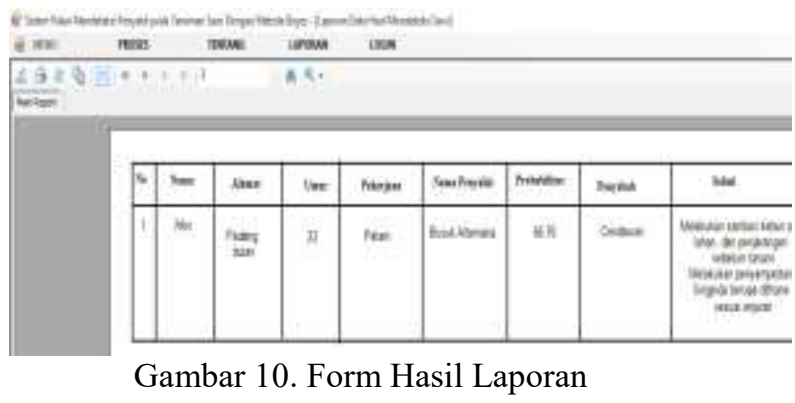

\section{KESIMPULAN}

Berdasarkan pembahasan dan implementasi yang di lakukan, maka dapat di peroleh beberapa kesimpulan :

1. Sistem pakar mendeteksi penyakit pada tanaman sayur dapat menentukan bobot gejala penyakit sawi.

2. Sistem pakar mendeteksi penyakit pada tanaman sayur sawi dapat menerapkan proses perhitungan setiap gejala.

3. Sistem pakar mendeteksi penyakit pada tanaman sayur sawi di bangun dengan menggunakan software seperti Visual Basic 2010, MYSQL sebagai penyimpanan data, Crystal Report sebagai software pendukung agar hasil deteksi penyakit dapat di cetak.

\section{REFERENSI}

[1] Azmi, Zulfian \& Yasin, Ferdi. 2017 Pengantar Sistem Pakar dan Metode. Jakarta: Mitra Wacana Media.

[2] Arhami, Muhammad. 2017. Konsep Dasar Sistem Pakar. Yogyakarta: Penerbit Andi.

[3] Budi,Samadi.2017. Tekniik Budidaya sawi.Yogyakarta:Penerbit Pustaka Mina.

[4] Ermatita. (April 2016). Analisis dan Perancangan Sistem Informasi Perpustakaan. Jurnal Sistem Informasi (JSI), 8 (1). Ditemukenal pada 02 Agustus 2018, dari http://ejournal.unsri.ac.id/index.php/jsi/index.

[5] Harison, \& Alexyusanderia. (Agustus 2014). Sistem Pakar Perawatan dan Perbaikan Ringan Mobil Bensin Menggunakan Video Tutorial Berbasis Web. Jurnal Momentum, 16 (02). Ditemukenali pada 02 Mei 2018 dari https://ejournal.itp.ac.id.

[6] Hartatik., Yasa, Ketut Putra I. (Juni 2015. Sistem Pakar Untuk Mendeteksi Hama Tanaman Jahe Menggunakan Teorema Bayes. Jurnal Ilmiah DASI, 16 (02). Ditemukenali pada 28 April 2018, dari https://media.neliti.com.

[7] Mahmudi, Ali., Rokhman, Moh. Miftakhur., Prasetio, Ahmad Eko. (Agustus 2016). Rancang Bangun Sistem Pakar Untuk Mendiagnosis Tanaman Cabai Menggunakan Metode Bayes. Jurnal Rekayasa dan Manajemen Sistem Informasi, 2 (2). Ditemukenali pada 30 April 2018, dari http://ejournal.uinsuska.ac.id/index.php/RMSI/article/view/261.

[8] Rika Rosnelly.2012."Sistem Pakar konsep dan teori", Yogyakarta: Andi Offset.

[9] Sihotang, Tamando Hengki., Panggabean, Erwin., \& Zebua, Herlina.(Maret 2018). Sistem Pakar Mendiagnosa Penyakit Herpes Zoster dengan Menggunakan Metode Teorema Bayes. Journal Of Informatic Pelita Nusantara, 3 (1). Ditemukenali pada 25 Juli 2018, dari http://ejurnal.pelitanusantara.ac.id/index.php/JIPN/art icle/view/284.

[10] Sutojo, T., Mulyanto, Edy., Suhartono, Vincent. 2010. Kecerdasan Buatan, 2010. Yogyakarta: Penerbit Andi. 